\title{
Current nut recommendation practices differ between health professionals in New Zealand
}

\author{
Rachel C Brown 1 ,* Andrew R Gray ${ }^{2}$, Lee Ching Yong ${ }^{1}$, Alex Chisholm ${ }^{1}$, Sook Ling Leong ${ }^{3}$ \\ and Siew Ling Tey \\ 'Department of Human Nutrition, University of Otago, PO Box 56, Dunedin, New Zealand: ${ }^{2}$ Department of \\ Preventive and Social Medicine, University of Otago, Dunedin, New Zealand: ${ }^{3}$ Department of Surgical Sciences, \\ University of Otago, Dunedin, New Zealand
}

Submitted 7 April 2017: Final revision received 29 September 2017: Accepted 24 October 2017: First published online 4 December 2017

\begin{abstract}
Objective: Despite evidence linking regular nut consumption with reduced chronic disease risk, population-level intakes remain low. Research suggests nutpromoting advice from doctors facilitates regular nut consumption. However, there is no information on current nut recommendation practices of health professionals. The aim of the present study was to examine the advice provided by health professionals regarding nut consumption.

Design: In this cross-sectional study, participants were invited to complete a survey including questions about their nut recommendation practices.

Setting: New Zealand (NZ).

Subjects: The NZ Electoral Roll was used to identify dietitians, general practitioners and practice nurses.

Results: In total 318 dietitians, 292 general practitioners and 149 practice nurses responded. Dietitians were more likely $(82.7 \%)$ to recommend patients increase consumption of nuts than general practitioners $(55.5 \%)$ and practice nurses (63.1\%; both $P<0 \cdot 001)$. The most popular nuts recommended were almonds, Brazil nuts and walnuts, with most health professionals recommending raw nuts. The most common recommendation for frequency of consumption by dietitians and practice nurses was to eat nuts every day, while general practitioners most frequently recommended 2-4 times weekly, although not statistically significantly different between professions. Dietitians recommended a significantly greater amount of nuts (median $30 \mathrm{~g} / \mathrm{d}$ ) than both general practitioners and practice nurses $(20 \mathrm{~g} / \mathrm{d}$; both $P<0 \cdot 001)$.

Conclusions: Dietitians were most likely to recommend consumption of nuts in accordance with current guidelines, but there are opportunities to improve the adoption of nut consumption recommendations for all professions. This may be a viable strategy for increasing population-level nut intakes to reduce chronic disease.
\end{abstract}

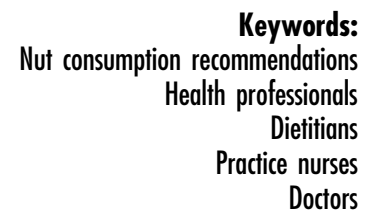

As nuts are rich in cis-unsaturated fats, vitamins, minerals, fibre and a number of phytonutrients ${ }^{(1-3)}$, their regular consumption is recommended as part of a number of dietary guidelines around the world ${ }^{(4-7)}$. This healthy nutrient profile of nuts likely contributes to the consistent negative associations seen between regular consumption of nuts and all-cause mortality over a given period of time $^{(8,9)}$ and, even more strongly, the risk of CVD ${ }^{(3,10-12)}$.

The National Heart Foundation of New Zealand (NZ) recommends the consumption of $30 \mathrm{~g}$ nuts daily as part of a cardioprotective diet ${ }^{(13)}$. This recommendation was recently reflected in eating and activity guidelines for NZ adults, which recommend eating a variety of nuts and replacing less healthy snack foods with $30 \mathrm{~g}$ nuts daily ${ }^{(4)}$.
A qualified health claim stating that eating $42 \mathrm{~g}$ nuts daily may reduce the risk of heart disease was approved in 2003 in the $\mathrm{USA}^{(14)}$. Nuts are also a prominent component of the cardioprotective Mediterranean diet ${ }^{(15)}$.

While these public health messages are an important step to promoting regular nut consumption, it is largely unknown how and even if these messages are incorporated into advice provided by health professionals. This is an important consideration because previous research has suggested that advice by a doctor to increase nut consumption is an important facilitator of regular nut intake $^{(16,17)}$. In a study among individuals with or at high risk of CVD and/or diabetes, $64 \%$ agreed that they would consume nuts on most days of the week if their doctor 
made such a recommendation; however, only $27 \%$ of respondents reported that their doctor did in fact advise them to eat nuts ${ }^{(17)}$.

The need to promote regular nut consumption among the general population has become even more apparent following population studies which indicate that regular nut consumption is much lower than recommended ${ }^{(18-21)}$. A nationally representative survey in NZ showed that only $6.9 \%$ of participants had consumed any whole nuts on the study day. These whole nut consumers had a mean intake of $40 \mathrm{~g} / \mathrm{d}$, achieving the recommended NZ and US intakes. However, the overall mean population intake was only $2 \cdot 8 \mathrm{~g} / \mathrm{d}$, less than one-tenth of the recommended $30 \mathrm{~g}$, based on a $24 \mathrm{~h} \mathrm{recall}^{(18)}$. In total only $29 \%$ of New Zealanders consumed any form of nut on the study day, with a mean individual intake of $17.9 \mathrm{~g}$, about one-half of the recommendation, and with a mean population intake of only $5 \mathrm{~g} / \mathrm{d}$, one-sixth of the recommendation. Similar findings in Europe and the USA suggest population-level nut intakes in a number of countries are much lower than the current guidelines and therefore need to be addressed ${ }^{(19,20)}$. Studies have indicated that nuts are resistant to monotony and so habitual consumption at recommended levels may be possible if consumers can be motivated to increase their consumption ${ }^{(22,23)}$.

One approach to improving nut intakes is the promotion of regular nut consumption by doctors and, potentially, other health professionals who are also likely to offer nutrition advice. Different population groups will have different levels of contact with different health professionals and so a multiprofession approach may allow promoting consumption more widely, and reinforcement by different groups of health professionals may improve uptake of health messages. Health professionals, including nurses, doctors, pharmacists and dentists, are all regularly included near the top of lists of trusted professions, with nurses frequently being listed as the most trusted professionals of all ${ }^{(24,25)}$. However, to the best of our knowledge, there is little information on whether health professionals provide advice consistent with nut consumption guidelines. Given that the advice from health professionals may be an important facilitator of nut consumption, gaining an understanding of current nut recommendation practices is important. Therefore, the present study aimed to assess the advice regarding nut consumption provided by health professionals in NZ, particularly dietitians, general practitioners and practice nurses.

\section{Materials and methods}

The study methods are described in detail in elsewhere ${ }^{(26)}$ and only essential details are presented here.

\section{Study design and participants}

This was a cross-sectional study of health professionals who were identified from the NZ Parliamentary Electoral Roll and was conducted during September-November 2014. Three professional occupations of interest were
Table 1 List of self-described occupations identified from the New Zealand Parliamentary Electoral Roll

\begin{tabular}{|c|c|c|}
\hline Dietitians & General practitioners & Practice nurses \\
\hline Dietitian & General practitioner & Practice nurse \\
\hline Clinical dietitian & GP & Nurse practitioner \\
\hline Clinical dietician & $\begin{array}{l}\text { General practitioner } \\
\text { doctor }\end{array}$ & Community nurse \\
\hline $\begin{array}{l}\text { Public health } \\
\text { dietician }\end{array}$ & Family doctor & Community nursing \\
\hline Sports dietician & $\begin{array}{l}\text { Medical general } \\
\text { practitioner }\end{array}$ & $\begin{array}{l}\text { Community health } \\
\text { nurse }\end{array}$ \\
\hline $\begin{array}{l}\text { Registered } \\
\text { dietitian }\end{array}$ & $\begin{array}{l}\text { General medical } \\
\text { practitioner } \\
\text { Family practitioner } \\
\text { Family physician }\end{array}$ & \\
\hline
\end{tabular}

identified, namely dietitians, general practitioners and practice nurses, reflecting those who were considered the most likely to provide dietary advice (Table 1 ).

An information sheet was posted to all participants and completion of the survey (online or the paper version) was taken as informed consent.

\section{Survey development}

The self-administered questionnaire consisted of three sections for demographics, perceptions of nuts and advice regarding nut consumption. The demographics section contained questions on sociodemographic characteristics including age, sex, ethnicity and number of years as a registered practitioner. Other questions from the other sections analysed here include: whether they recommended increasing or decreasing nut consumption for some patients and the types, forms and quantity of nuts that they recommended. The types of nuts included tree nuts and peanuts, but not coconuts or chestnuts as these differ in nutritional composition. There was a combination of open-ended and multiple-choice questions and multiple-response questions. For example, the question on the recommended frequency of nut consumption had six choices ranging from every day to once or less than once per month. The question on amounts of nuts recommended was an open-ended question. The questionnaire was pre-tested and modified where appropriate using feedback from twelve health professionals including six dietitians, two general practitioners and four practice nurses, establishing both face and content validity. Both an online version and a paper copy of the questionnaire were available. For the online version of the questionnaire, Survey Gizmo $^{(}$(Widgix Software, LLC, Boulder, CO, USA) was used.

\section{Survey administration}

Recruitment used an adaptation of Dillman's four-stage tailored design method for conducting a mail survey ${ }^{(27)}$ with an invitation to participate and the URL for the survey, followed seven days later by a postcard thanking those who had already responded and reminding those who had not. Then, after another eight days, a paper version of the questionnaire was sent to the remaining non-respondents. 
A second postcard was sent to all recipients of the third mail-out another twelve days later, thanking those who had responded and reminding those who had not. Users were provided with a login code so that each participant could complete the questionnaire once only. The survey remained open for two and half months.

\section{Statistical analysis}

The sample size calculations are presented in detail in elsewhere $^{(26)}$, but briefly, 184 usable responses were required for each occupation (equivalent to 368, allowing for a $50 \%$ response rate). Sufficient numbers were not available from the Electoral Roll search for all three occupations and all identified electors were included in the sample for a total of 1440 health professionals comprising 578 dietitians, 596 general practitioners and 266 practice nurses, giving $95 \%$ CI half-widths, assuming $50 \%$ participation, of $6.0,5.9$ and $8.9 \%$, respectively, and with the greater numbers of dietitians and general practitioners providing approximately the same power as the original numbers for comparisons between either of these larger groups and the smaller number of practice nurses.

Baseline characteristics of respondents are presented as arithmetic means and standard deviations or medians and interquartile ranges for continuous variables. Categorical data are presented as frequencies and percentages. For analysis purposes, ethnicity was categorised as follows: Māori, European, Asian and other (comprising the Pacific, Middle Eastern/Latin American/African (MELAA), other, and residual categories in Statistics New Zealand's level one ethnicity categories) ${ }^{(28)}$. Characteristics were compared between health professions using a $\chi^{2}$ test for sex, a one-way ANOVA for age, Fisher's exact test for ethnicity and the Kruskal-Wallis test for years as a registered practitioner.

For comparisons between health professions of binary outcome variables regarding nut recommendations, unadjusted analyses were initially conducted using logistic regression when there was a minimum of twenty participants with responses at each level (following Peduzzi et $a l .{ }^{(29)}$ given the two parameters being estimated). If this was not the case, $\chi^{2}$ tests were used unless more than $20 \%$ of cells had expected counts below 5, in which case Fisher's exact test was used ${ }^{(30)}$. For outcomes compared using logistic regression, these were further adjusted for age (continuous), sex (male/female) and ethnicity (four levels) providing there were at least seventy participants with responses at each level (again, following Peduzzi et al. given the seven parameters being estimated). For ordinal variables, such as the percentage of patients whom health professionals recommend consume more nuts $(<20 \%, \quad 20-39 \%, \quad 40-59 \%, \quad 60-79 \%, \quad \geq 80 \%)$, ordinal logistic regression was used for unadjusted models only and proportionality was assessed using a generalised ordinal logistic regression model. For all models with age included as an independent variable, age-squared was added to the model as a check for non-linearity and retained when statistically significant. For linear regression models, residuals were inspected for evidence of departures from normality or homoscedasticity, with log-transformations investigated and retained when this improved the satisfaction of model assumptions. Where model assumptions were not satisfied despite log-transformations, quantile regression was used to model medians instead. Quantile regression was used to compare median frequencies and gram amounts recommended between health professions, both without and with adjustment for age, sex and ethnicity. Where interactions were considered plausible, these were investigated and noted in the text irrespective of statistical significance. Missing responses were relatively infrequent for each question and no special treatment for these was performed. The statistical software package Stata version 14.2 was used for all statistical analyses. All statistical tests were two-sided and $P<0.05$ was considered statistically significant. Pairwise comparisons between levels of categorical variables were conducted only where the overall Wald test was statistically significant. No formal adjustment for multiple comparisons was performed in this exploratory study. Consequently, marginally statistically significant results and results not consistent with other findings should be interpreted with caution.

\section{Results}

\section{Response rate}

A total of 759 of the 1440 (53\%) health professionals completed the questionnaire, which was slightly higher than the anticipated response rate of $50 \%$. The response rates were not significantly different between health professions, being $55 \%$ for dietitians, $49 \%$ for general practitioners and $56 \%$ for practice nurses $\left(\chi^{2} P=0.058\right)$. No reasons were given by participants for not completing the questionnaire.

\section{Participant characteristics}

The demographic characteristics of the respondents are outlined in Table 2. Dietitians comprised $42 \%$ of the total sample, general practitioners $38 \%$ and practice nurses the remaining $20 \%$. The majority of respondents were female (81\%) with this imbalance especially prevalent in dietitians (97\%) and practice nurses (96\%) compared with general practitioners $\left(57 \% ; \chi^{2} P<0 \cdot 001\right)$. Mean age was 47.3 years, with the dietitian group on average being over 8 years younger than both general practitioners and practice nurses (one-way ANOVA overall $P<0 \cdot 001$, post hoc tests $P<0.001$ for both pairwise comparisons involving dietitians and $P=0.769$ for general practitioners $v$. practice nurses). The respondents had a median of 20 years as registered practitioners, with practice nurses having been registered 5 and 12 years longer than general practitioners 
Table 2 Characteristics of survey respondents: health professionals, New Zealand, September-November 2014

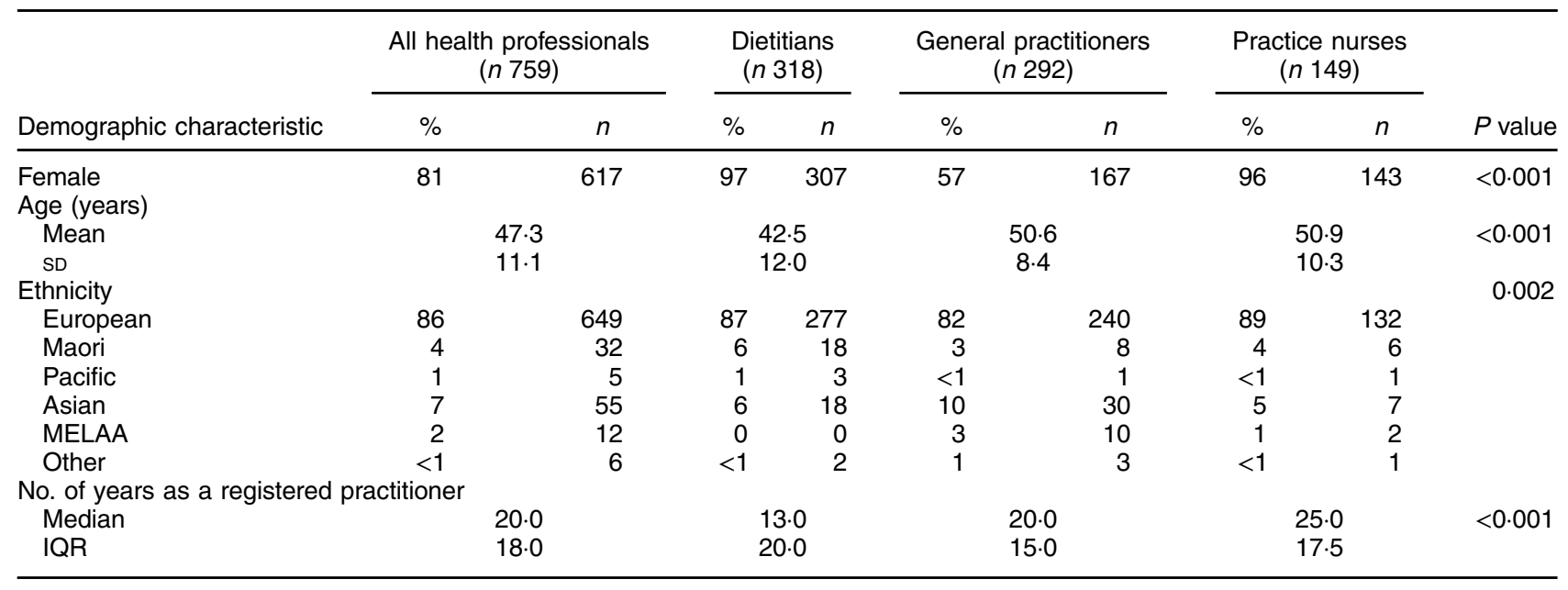

MELAA, Middle Eastern/Latin American/African; IQR, interquartile range.

$P$ values from $X^{2}$ test (sex), one-way ANOVA (age), Fisher's exact test (ethnicity) and Kruskal-Wallis test (years registered).

and dietitians, respectively (Kruskal-Wallis $P<0 \cdot 001$, all post hoc Dunn's tests $P<0 \cdot 001)$. The majority of respondents were NZ European (86\%). This varied between professional groups (Fisher's exact $P=0.002$ ) with evidence of higher percentages of general practitioners being Asian (10.4 v. $4.7 \%$ for practice nurses and $5.7 \%$ for dietitians; $\left.\chi^{2} P=0.034\right)$ and MELAA $(3.5 v .1 .3 \%$ for practice nurses and $0.0 \%$ for dietitians; Fisher's exact $P=0.001$ ) when each was compared with the rest of the ethnicities.

\section{Percentage of bealth professionals recommending patients to eat more nuts, fewer nuts or not mentioning nuts}

Respondents were asked if they recommended that some of their patients should eat more nuts, fewer nuts, or did not mention nuts at all. There was an overall difference between the three groups of health professionals in terms of the percentage who would recommend patients to eat more nuts (i.e. are nut promoters; overall $P<0.001$ for both unadjusted and adjusted models), with pairwise comparisons showing that dietitians $(82.7 \%)$ were more likely to recommend the consumption of more nuts compared with $63.1 \%$ of practice nurses and $55.5 \%$ of general practitioners (both pairwise $P<0.001$ from both unadjusted and adjusted models) and with no differences between the practice nurses and general practitioners ( $P \geq 0.126$ from unadjusted and adjusted models). From the adjusted model, females were more likely than males to recommend the consumption of more nuts (OR $=1 \cdot 68$; $95 \%$ CI 1.09, 2.58; $P=0 \cdot 019)$ with no evidence of an association with age $(P=0.272)$ or with ethnicity $(P=0 \cdot 800)$. No evidence was found that the sex difference varied by profession when an interaction was added to the model $(P=0 \cdot 775)$.

Although fewer general practitioners said they recommended that some of their patients eat fewer nuts (e.g. reduce amounts or frequency; $26.7 \%$ ), compared with both practice nurses (45.0\%) and dietitians (41.2\%), the differences between health professionals were not statistically significant (overall $P=0 \cdot 064$ ). Females were more likely than males to recommend that some of their patients eat fewer nuts $(\mathrm{OR}=2 \cdot 04 ; 95 \%$ CI 1.24, 3.35; $P=0 \cdot 005)$. There was evidence for a U-shape in the association with age with the numerical minimum at age 49 years (age $P=0 \cdot 019$, age-squared $P=0 \cdot 023$ ). The odds of recommending the consumption of fewer nuts was lowest at 49 years and comparisons with the youngest respondents were statistically significant (OR for 19-year-old (the youngest respondent) $v$. 49-year-old $=3 \cdot 20 ; 95 \%$ CI $1 \cdot 21,8 \cdot 51$ ) but not quite statistically significant compared with the oldest respondents (OR for 77-year-old (the oldest respondent) $v$. 49 -year-old $=2 \cdot 89 ; 95 \%$ CI $0 \cdot 95,8 \cdot 77)$. There was no evidence of an association with ethnicity ( $P=0 \cdot 162$; Table 3$)$.

There was a significant difference between health professionals regarding the percentage who choose not to mention nuts to patients (overall $P<0.001$ from unadjusted and adjusted models). Only $11.0 \%$ of dietitians did not mention nut consumption, which was significantly less than the $25.5 \%$ of practice nurses and $39.0 \%$ of general practitioners (both pairwise $P<0.001$ from both unadjusted and adjusted models). There was no difference between general practitioners and practice nurses after adjustment (unadjusted $P=0 \cdot 005$, adjusted $P=0 \cdot 196)$. Females were less likely than males to not mention nuts $(\mathrm{OR}=0.49 ; 95 \% \mathrm{CI}$ $0.32,0 \cdot 77, P=0.002)$. There was no evidence of an association with ethnicity $(P=0 \cdot 081)$ or age $(P=0.562)$, nor a profession $\times$ sex interaction $(P=0.908$; Table 3$)$.

Respondents were also asked to estimate the percentage of patients they advise to eat more nuts. The median response for both dietitians and practice nurses was 20-39\% of respondents, compared with $<20 \%$ of general practitioners. There was a significant overall difference between health professions (overall ordinal logistic regression $P<0.001$; no evidence of non-proportionality). Pairwise comparison showed significant differences between all health 
professionals (all pairwise $P \leq 0 \cdot 001$ ), with general practitioners having only about one-fifth the odds of making recommendations to eat a larger proportion compared with dietitians $(\mathrm{OR}=0.22 ; 95 \% \mathrm{CI} 0.15,0.33, P<0.001)$ and practice nurses having about one-half the odds compared with dietitians (OR=0.49; 95\% CI 0.32, 0.76, P=0.001; Table 3). Adjusted models were not able to investigate proportionality due to the numbers of events but similar results for professions were observed in models assuming proportionality, with no evidence for associations with age, sex or ethnicity (results not shown).

Type of nuts and nut butters recommended by nutpromoting health professionals

The most common nuts recommended by health professionals were almonds, Brazil nuts and walnuts (Table 4). Significantly more dietitians recommend nuts in general compared with general practitioners and practice nurses (both pairwise $P<0 \cdot 001$ ). Other significant differences between health professionals were for almonds, Brazil nuts, peanuts and walnuts (all overall $P \leq 0.035$ from adjusted models). Pairwise comparisons showed that dietitians are less likely to recommend almonds compared with general practitioners and practice nurses (both pairwise $P \leq 0.007$ ), and more dietitians would recommend peanuts compared with the other two health professions (both pairwise $P \leq 0.040$ ). In addition, fewer dietitians recommend Brazil nuts compared with general practitioners (pairwise $P=0 \cdot 005$ ). Further, significantly more practice nurses recommend walnuts than both dietitians and general practitioners (both pairwise $P \leq 0.036$ ).

Overall, fewer health professionals reported recommending nut butters in general (30.6\%) compared with nuts in general (69.4\%). Significantly more dietitians (39\%) would recommend nut butters in general than both general practitioners (19\%) and practice nurses (27\%; both pairwise $P \leq 0.014)$. In addition, significantly more dietitians (54\%) would recommend peanut butter compared with only $14 \%$ of general practitioners and $27 \%$ of practice nurses (both pairwise $P<0 \cdot 001$ ). The difference between general practitioners and practice nurses was also significant $(P=0 \cdot 012)$. Of the tree nut butters, almond butter was the most frequently recommended by health professionals $(12.5 \%)$, while cashew butter, hazelnut butter and walnut butter were recommended by less than $4 \%$ of health professionals. The only age, sex or ethnicity effects from adjusted models were for walnuts (overall $P=0.007$ ), where those of Asian ethnicity were more likely to recommend walnuts than those of both European $(\mathrm{OR}=3.95 ; 95 \%$ CI $1.78,8.75 ; P=0.001)$ and Māori $(\mathrm{OR}=5.53 ; 95 \%$ CI $1.65,18.53 ; P=0.006)$ ethnicity.

\section{Nut forms recommended by nut-promoting health professionals}

The most commonly recommended form of nut by all three health professionals were raw nuts (91.7\%; Table 4). 
Table 4 Types of nuts and nut butters recommended by nut-promoting health professionals*, New Zealand, September-November 2014

\begin{tabular}{|c|c|c|c|c|c|c|c|c|c|c|}
\hline \multirow[b]{2}{*}{ Type/form of nut or nut butter } & \multicolumn{2}{|c|}{$\begin{array}{l}\text { All health professionals } \\
\qquad(n 519)\end{array}$} & \multicolumn{2}{|c|}{$\begin{array}{l}\text { Dietitians } \\
(n 263)\end{array}$} & \multicolumn{2}{|c|}{$\begin{array}{c}\text { General practitioners } \\
(n 162)\end{array}$} & \multicolumn{2}{|c|}{$\begin{array}{l}\text { Practice nurses } \\
\qquad(n 94)\end{array}$} & \multirow{2}{*}{$\begin{array}{l}\text { Unadjusted } \\
P \text { value } \dagger\end{array}$} & \multirow{2}{*}{$\begin{array}{l}\text { Adjusted } \\
P \text { valuef }\end{array}$} \\
\hline & $\%$ & $n$ & $\%$ & $n$ & $\%$ & $n$ & $\%$ & $n$ & & \\
\hline \multicolumn{11}{|l|}{ Type of nut } \\
\hline Almond & $57 \cdot 0$ & 296 & $46 \cdot 8^{a}$ & 123 & $63 \cdot 6^{b}$ & 103 & $74 \cdot 5^{\mathrm{b}}$ & 70 & $<0.001 \S$ & $<0.001 \S$ \\
\hline Brazil & $47 \cdot 2$ & 245 & $40 \cdot 7^{a}$ & 107 & $56 \cdot 2^{b}$ & 91 & $50 \cdot 0^{a, b}$ & 47 & $0.007 \S$ & $0.015 \S$ \\
\hline Cashew & $15 \cdot 8$ & 82 & $15 \cdot 2$ & 40 & $16 \cdot 7$ & 27 & $16 \cdot 0$ & 15 & $0.922 \S$ & $0.972 \S$ \\
\hline Hazelnut & 17.5 & 91 & $13 \cdot 7$ & 36 & $19 \cdot 8$ & 32 & 24.5 & 23 & $0.044 \S$ & $0.091 \S$ \\
\hline Macadamia & $10 \cdot 8$ & 56 & $7 \cdot 2$ & 19 & $12 \cdot 3$ & 20 & $18 \cdot 1$ & 17 & $0.013 \S$ & \\
\hline Peanut & 14.6 & 76 & $19 \cdot 8^{a}$ & 52 & $8.0^{b}$ & 13 & $11 \cdot 7^{\mathrm{b}}$ & 11 & $0.004 \S$ & $<0.001 \S$ \\
\hline Pecan & $9 \cdot 1$ & 47 & $6 \cdot 8$ & 18 & $13 \cdot 6$ & 22 & $7 \cdot 4$ & 7 & $0.058 \S$ & \\
\hline Pine nut & 7.9 & 41 & $2 \cdot 7$ & 7 & 10.5 & 17 & $18 \cdot 1$ & 17 & $<0.001 \S$ & \\
\hline Pistachio & $6 \cdot 7$ & 35 & 3.0 & 8 & 8.6 & 14 & $13 \cdot 8$ & 13 & $0.002 \S$ & \\
\hline Walnut & $44 \cdot 3$ & 230 & $38 \cdot 4^{a}$ & 101 & $46 \cdot 9^{a}$ & 76 & $56 \cdot 4^{\mathrm{b}}$ & 53 & $0.008 \S$ & $0.037 \S$ \\
\hline Nuts in general & 69.4 & 360 & $84 \cdot 0^{a}$ & 221 & $53 \cdot 1^{\mathrm{b}}$ & 86 & $56 \cdot 4^{\mathrm{b}}$ & 53 & $<0.001 \S$ & $<0.001 \S$ \\
\hline \multicolumn{11}{|l|}{ Type of nut butter } \\
\hline Almond butter & 12.5 & 65 & $12 \cdot 2$ & 32 & 14.2 & 23 & $10 \cdot 6$ & 10 & $0.688 \S$ & \\
\hline Cashew butter & 3.5 & 18 & 3.4 & 9 & $4 \cdot 3$ & 7 & $2 \cdot 1$ & 2 & $0.651 \|$ & \\
\hline Hazelnut butter & $3 \cdot 1$ & 16 & $2 \cdot 3$ & 6 & $4 \cdot 3$ & 7 & $3 \cdot 2$ & 3 & 0.496 & \\
\hline Peanut butter & $36 \cdot 4$ & 189 & $53 \cdot 6^{\mathrm{a}}$ & 141 & $14 \cdot 2^{b}$ & 23 & $26 \cdot 6^{\mathrm{c}}$ & 25 & $<0.001 \S$ & $<0.001 \S$ \\
\hline Walnut butter & 3.7 & 19 & $0.8^{a}$ & 2 & $8 \cdot 6^{\mathrm{b}}$ & 14 & $3 \cdot 2^{a, b}$ & 3 & $<0.001 \|$ & \\
\hline Nut butters in general & $30 \cdot 6$ & 159 & $39 \cdot 2^{\mathrm{a}}$ & 103 & $19 \cdot 1^{b}$ & 31 & $26 \cdot 6^{\mathrm{b}}$ & 25 & $<0.001 \S$ & $<0.001$ \\
\hline \multicolumn{11}{|l|}{ Form of nut } \\
\hline Raw & 91.7 & 476 & 89.0 & 234 & 93.8 & 152 & $95 \cdot 7$ & 90 & 0.071 & \\
\hline Roasted with oil & 11.9 & 62 & $18 \cdot 3$ & 48 & 8.0 & 13 & $1 \cdot 1$ & 1 & $<0.001$ & \\
\hline Dry roasted & $36 \cdot 4$ & 189 & $44 \cdot 5^{a}$ & 117 & $31.5^{\mathrm{b}}$ & 51 & $22 \cdot 3^{\mathrm{b}}$ & 21 & $<0.001$ & $<0.001$ \\
\hline Roasted, unsalted & 43.5 & 226 & $45 \cdot 2$ & 119 & $42 \cdot 0$ & 68 & 41.5 & 39 & 0.729 & 0.268 \\
\hline Roasted, salted & $6 \cdot 6$ & 34 & $9 \cdot 1^{a}$ & 24 & $6 \cdot 2^{\mathrm{a}}$ & 10 & $0.0^{\mathrm{b}}$ & 0 & $0.002 \S$ & \\
\hline As part of a dish or recipe & 24.7 & 128 & $32 \cdot 7^{\mathrm{a}}$ & 86 & $17 \cdot 3^{b}$ & 28 & $14 \cdot 9^{b}$ & 14 & $<0.001$ & $<0.001$ \\
\hline
\end{tabular}

a,b,c Percentage values within a row with unlike superscript letters were significantly different after adjustment for age, sex and ethnicity $(P<0.05)$.

${ }^{*}$ Respondents could choose multiple responses.

$\dagger P$ value for difference between health professionals.

$\ddagger$ Adjusted for age, sex and ethnicity where there are sufficient responses.

§Indicates logistic regression.

$\|$ Indicates $x^{2}$ test.

This was followed by roasted, unsalted nuts ( $43.5 \%$ ), dry roasted (36.4\%), as part of a dish or recipe (24.7\%) and roasted with oil (11.9\%), with the least popular form being roasted and salted (6.6\%). There were overall differences between health professions for the percentage recommending dry roasted nuts, and as part of a dish (both overall $P<0 \cdot 001$ ). Pairwise comparisons showed that more dietitians recommend dry roasted nuts compared with general practitioners $(P=0.023)$ and practice nurses $(P<0.001)$. In addition, more general practitioners recommend this form of nut compared with practice nurses $(P=0 \cdot 032)$. Compared with both general practitioners and practice nurses, more dietitians recommend nuts as part of a dish. Exact logistic regression was used to compare recommending roasted, salted nuts and found evidence of an overall difference $(P=0.002)$, with practice nurses less likely to recommend this form than both dietitians $(P=0.001)$ and general practitioners $(P=0.015)$. The only age, sex or ethnicity effects from the adjusted models were that female professionals were less likely to recommend nuts roasted with oil $(\mathrm{OR}=0 \cdot 28,95 \% \mathrm{CI} 0 \cdot 11$, $0.71 ; P=0.007)$ and older professionals were more likely to recommend both roasted, unsalted nuts (OR per 10 -year age increase $=1.26 ; 95 \%$ CI 1.06, 1.50; $P=0.008$ ) and nuts in a dish (OR per 10-year age increase $=1.47$; $95 \%$ CI 1.21, 1.79; $P<0 \cdot 001)$.

\section{Frequency and quantity of nuts recommended by nut-promoting bealth professionals}

The plurality of dietitians and practice nurses recommended patients eat nuts every day ( 40.4 and $39.1 \%$ ), followed by 2-4 times per week (37.7 and $35.9 \%)$. The plurality of general practitioners recommended a frequency of 2-4 times per week (35.4\%), followed by every day $(32.9 \%$; Table 5). There was no evidence of a difference in median frequencies between groups (23.9 servings/month for all professional groups, equivalent to 5.5 servings/week) in both the adjusted and unadjusted models (quantile regression overall $P=1.000$ for both unadjusted and adjusted models).

There was evidence for a difference in the median amounts of nuts recommended by the three different types of health professional (overall $P<0.001$ for both unadjusted and adjusted). The quantity of nuts recommended by dietitians (median $30 \mathrm{~g}$ ) was significantly higher compared with both general practitioners $(20 \mathrm{~g})$ and practice nurses ( $20 \mathrm{~g}$; both pairwise $P \leq 0.001$ for both unadjusted and adjusted models). There was no difference between 
Table 5 Recommended frequency of nut consumption by nut-promoting health professionals*, New Zealand, September-November 2014

\begin{tabular}{|c|c|c|c|c|c|c|}
\hline \multirow[b]{2}{*}{ Recommended nut consumption } & \multicolumn{2}{|c|}{$\begin{array}{l}\text { Dietitians } \\
\text { (n 255) }\end{array}$} & \multicolumn{2}{|c|}{$\begin{array}{c}\text { General practitioners } \\
\text { ( } n \text { 158) }\end{array}$} & \multicolumn{2}{|c|}{$\begin{array}{l}\text { Practice nurses } \\
\qquad(n \text { 92) }\end{array}$} \\
\hline & $\%$ & $n$ & $\%$ & $n$ & $\%$ & $n$ \\
\hline Every day* & $40 \cdot 4$ & 103 & $32 \cdot 9$ & 52 & $39 \cdot 1$ & 36 \\
\hline $5-6$ times per week & 18.4 & 47 & $19 \cdot 0$ & 30 & 17.4 & 16 \\
\hline 2-4 times per week & 37.7 & 96 & $35 \cdot 4$ & 56 & $35 \cdot 9$ & 33 \\
\hline Once per week & 1.6 & 4 & 2.5 & 4 & 4.4 & 4 \\
\hline Several times per month & 1.2 & 3 & 1.9 & 3 & $1 \cdot 1$ & 1 \\
\hline \multirow[t]{2}{*}{ Once or less than once per month } & 0.8 & 2 & 8.2 & 13 & $2 \cdot 2$ & 2 \\
\hline & Median & IQR & Median & IQR & Median & IQR \\
\hline Recommended frequency (servings/month) & 23.9 & 17.4 & 23.9 & 17.4 & 23.9 & $17 \cdot 4$ \\
\hline Recommended grams per day $\dagger$ & 30 & 13 & 20 & 10 & 20 & 10 \\
\hline
\end{tabular}

$\mathrm{IQR}$, interquartile range.

${ }^{*}$ Respondents chose from a multiple-choice question.

†These data are from an open-ended question.

general practitioners and practice nurses (quantile regression overall $P=1.000$ for unadjusted and adjusted models).

\section{Discussion}

To the best of our knowledge, the present study is the first to examine nut recommendation practices among different groups of health professionals. It is plausible that the advice provided by health professionals would influence nut consumption patterns among the general public. Indeed, previous research has suggested that individuals would consume nuts on most days of the week if advised to do so by a doctor ${ }^{(16,17)}$. Other health professionals such as dietitians and practice nurses also offer dietary advice; therefore, also examining these professions was considered more informative than investigating only doctors, especially given high levels of public trust in nurses ${ }^{(24,25)}$. Results may be generalisable to health professionals in other countries with similar characteristics to NZ and possibly more broadly with greater caution.

Overall, $68 \%$ of health professionals recommended at least some of their patients to eat more nuts, with dietitians significantly more likely to do so compared to both general practitioners and practice nurses. This most likely reflects the specialised nutrition training of dietitians and the focus of their work. Interestingly, about $40 \%$ of dietitians also recommended that some of their patients should eat fewer nuts. The reasons for recommending that some patients eat fewer nuts are reported in detail elsewhere ${ }^{(26)}$, but in brief these included the fact that nuts are high in energy and fat, cause weight gain, people may have allergies and they may be too expensive. Participants were also able to comment further regarding this recommendation. Dietitians were more likely to do so, with the majority of additional comments pertaining to the individualised dietary requirements of specific patients. For example, a reason dietitians commonly gave for recommending some patients eat fewer nuts was because the $\mathrm{K}$ and $\mathrm{P}$ concentrations were too high for patients with renal conditions. This specific advice again reflects the specialised nutrition training of dietitians and the nutrition emphasis of their consultations.

There is a distinct lack of research with which the results of the present study can be compared. Previously, Pawlak et al. reported among low-income participants that the strongest agreement regarding barriers and facilitators was with the statement 'I would eat nuts on most days of the week if my doctor recommended me to do so, ${ }^{,(16)}$. In a further study by this group, among those with or at risk of CVD and diabetes, $64 \%$ of participants also agreed or strongly agreed that they would consume nuts on most days of the week if their doctor made such a recommendation $^{(17)}$. Therefore, the nut recommendation practices of health professionals appear to be an important influence on nut consumption. However, in that study, only $27 \%$ of participants agreed or strongly agreed that their doctor advises them to eat nuts ${ }^{(17)}$. In our study, $55 \%$ of general practitioners reported they recommend some patients to eat more nuts, which was lower compared with both practice nurses and dietitians, although only significantly so compared with the latter. The present study was not designed to investigate differences between messages given and those received, but given the large difference observed, this is worthy of further research. Exploring strategies whereby more health professionals, particularly general practitioners and practice nurses, are encouraged to promote nut consumption to their patients is also justified to complement other approaches such as information from nutritionists, public health campaigns and the media. Given our results, improving knowledge of the health benefits of regular nut consumption should form the basis of such approaches.

The most popular nuts recommended by health professionals in the present study were almonds, Brazil nuts and walnuts. It is possible that these nuts are most 
commonly recommended, in part, due to the attention they receive in the lay media. For example, the Almond Boards of both California and Australia have active marketing campaigns, which are likely to increase the profile of this nut type. Walnuts may receive more attention than some other nuts because they are a good source of $\alpha$-linolenic acid, a plant-based $n-3$ fat, that has received much attention in both the scientific and lay literature for reducing the risk of $\mathrm{CVD}^{(31,32)}$. In addition, walnuts grow in many parts of NZ, often in domestic gardens, thus allowing for the possibility of access to fresh nuts at little cost. NZ soils are low in $\mathrm{Se}^{(33)}$. With this knowledge in mind, health professionals in NZ may be more likely to recommend Brazil nuts as an important source of Se. It would be interesting to compare recommendations regarding Brazil nuts among health professionals in NZ with those from other countries where obtaining adequate intake of Se is less problematic.

Interestingly, dietitians were more likely to recommend nuts in general, possibly reflecting a better understanding of the overall health benefits of nuts. In the 2008/09 NZ Adult Nutrition Survey which assessed nut intake by $24 \mathrm{~h}$ recalls, the most popular nuts consumed were almonds, mixed nuts, cashews, Brazil nuts and walnuts ${ }^{(18)}$. This largely reflects the types of nuts recommended by health professionals in the current study.

The National Heart Foundation of NZ recommends the consumption of $30 \mathrm{~g}$ nuts daily ${ }^{(13)}$. In the present study, the most common recommendation by dietitians and practice nurses was to eat nuts on a daily basis, whereas the majority of general practitioners recommended patients eat nuts 2-4 times weekly. Although this difference was not statistically significant, it is worth noting that fewer than half of general practitioners offered a message consistent with the National Heart Foundation's guidelines. Over onethird of each health profession recommended nuts to be eaten every second day. Therefore, a future direction for educating health professionals could be the emphasis on nuts as a literally 'everyday' food, which can also be used to replace less healthful snacks. The median quantity of nuts recommended by dietitians was $30 \mathrm{~g}$ daily, which was significantly more than both general practitioners and practice nurses (both $10 \mathrm{~g} / \mathrm{d}$ less). The advice provided by dietitians most closely reflects current recommendations in NZ $(30 \mathrm{~g} / \mathrm{d})$, and again this is likely to be due to their nutrition training. Improving the knowledge of nut consumption guidelines should form the basis of continuing education material for general practitioners and practice nurses but there is also room for improvement among dietitians despite their additional training.

In NZ, the consumption of nuts in their raw form is recommended ${ }^{(13)}$ and raw nuts were the most commonly recommended (over $90 \%$ ) nut form by all health professions in the present study. A substantial number of health professionals also recommended dry roasted nuts, with significantly more dietitians recommending this option compared with both general practitioners and practice nurses. Research suggests that roasting at temperatures below $140^{\circ} \mathrm{C}$ does not negatively impact the nutrient content of nuts ${ }^{(34-36)}$. The temperatures used to commercially roast nuts are typically within this range. Roasted and salted nuts were least likely to be recommended by all health professions. This likely reflects the potential negative effects of $\mathrm{Na}$ on health ${ }^{(37)}$. Previous research has indicated that roasted nuts may be considered more palatable by some consumers ${ }^{(38,39)}$. A recent study showed that lightly salting (133 mg Na/100 g) and dry roasting nuts did not negate the health benefits seen with raw nut consumption ${ }^{(40)}$. The amount of $\mathrm{Na}$ used in that study was similar to lightly salted commercial varieties (about $145 \mathrm{mg} \mathrm{Na} / 100 \mathrm{~g}$ ). Taken together, this suggests that health professionals should continue to recommend raw nuts, but could broaden their recommendations for patients who dislike the taste or texture of raw nuts to include dry roasted and lightly salted nuts.

Health professionals on the whole were much less likely to recommend nut butters than whole nuts. It appears nut butters are perceived as less healthy than whole nuts by this group of health professionals. Research on the health effects of regular peanut butter consumption is limited and conflicting, with some studies reporting positive effects $^{(41,42)}$, while others do not ${ }^{(43,44)}$. Given that peanut butter is relatively inexpensive and easy to consume, it could provide a viable alternative, especially for those on a low income or with mastication difficulties. The income aspect is especially important given the disproportionally higher rates of chronic disease among those in the most deprived households ${ }^{(45)}$. Also, nut butters may contain added sugar and fat which may deter some health professionals from recommending such products. Therefore, more research on the health effects of peanut butter (both natural and containing added fats and sugar) and other nut butters, is required, so that evidence-based recommendations can be developed.

The present study should be interpreted with several limitations and strengths in mind. First, the cross-sectional design means causal inferences cannot be drawn, but information from the study allows for generation of hypotheses for future research. The response rate was $53 \%$, which is comparable to other mail surveys in Australasia $^{(46,47)}$, but there remains the possibility that nonresponders were different from responders. However, while means, medians and percentages might have been affected by interest in the survey topic, there are no clear reasons why the observed associations would differ between responders and non-responders. While studies investigating response biases in associations specific to health professionals are lacking, previous research has found no evidence for significant biases in associations involving health behaviours in the general public ${ }^{(48-50)}$. The majority of respondents were female, which may limit the generalisability of the descriptive results to health 
professionals in general. However, to ensure that sex was not confounding associations, there was adjustment for sex in regression models whenever possible, along with age and ethnicity as further confounders. All three of these variables were found to be associated with some outcomes. Another limitation is that these professionals were identified based on their occupation description and despite our careful searching, some eligible health professionals will not have been identified either through overly general occupations in the Electoral Roll (e.g. 'doctor' or 'nurse') or possibly through descriptions that were not identified. The use of the Electoral Roll, rather than directly approaching professional bodies, changed the sampling frame from registered professionals to those with appropriate descriptions for their occupation in the Electoral Roll. While this enabled us to contact potential respondents directly and to send thank you and reminder messages, which are part of Dillman's approach to maximise survey response and so try to decrease biases from non-response, it is possible that the professionals identified in this way differ systematically from those not so identifiable, although we cannot think of reasons for systematic differences in the outcomes from this beyond the potential confounders included in models (age, sex and ethnicity). A further limitation is that we cannot account for the mixture of patients each profession typically encounters and it is possible that some of the observed differences in responses could be attributable to this. In particular, promoting higher or lower levels of nut consumption could depend on patient characteristics and the current nut consumption levels of these patients, which could vary between general practitioners and practice nurses compared with dietitians. These results may also not generalise to countries with different health-care systems to NZ or to other health-care professions. It is also important to acknowledge that people receive information about nuts from other sources such as the media, nutritionists and public health campaigns, which may also influence nut consumption and potentially the advice they receive from health-care professionals.

A strength of the research was the careful development of the questionnaire to optimise content and face validity, including the involvement of six dietitians, two general practitioners and four practice nurses, as well as one of the co-authors being a registered dietitian. Further, the use of a rigorous mail survey utilising a modified version of Dillman's tailored design method with a mixed-mode approach resulted in a response rate that was slightly higher than anticipated in the sample size calculations and reduces our concerns about response biases.

\section{Conclusion}

The present study provides unique information on the current nut recommendation practices of health professionals in NZ. Dietitians were more likely to recommend nuts in line with current recommendations compared with general practitioners and practice nurses. This is likely to reflect dietitian's specialised nutrition training, but there are still gaps between the recommendations and dietetic practice. Improving knowledge on the health benefits of nuts among health professionals is likely to influence nut recommendation practices to positively impact nut consumption among the general public, given previous research which suggests that the public would consume more nuts if advised to do so by a doctor. Increasing nut consumption, especially when they are in place of less healthful snacks, is likely to lower the risk of chronic disease. Nurses may be particularly effective in this role given the high levels of trust they have with the public.

\section{Acknowledgements}

Acknowledgements: The authors would like to thank the participants for their commitment and enthusiasm in participating in this study. Financial support: This study was supported by internal funds from the Department of Human Nutrition, University of Otago. The funder had no role in the design, analysis or writing of this article. Conflict of interest: None. Authorship: R.C.B., A.R.G. and A.C. formulated the research questions; all authors contributed to the design the study; L.C.Y. was responsible for carrying out the study; R.C.B. and A.R.G. were responsible for analysing the data; all authors contributed to the writing of the manuscript. Ethics of buman subject participation: The study was conducted according to the guidelines laid down in the 1964 Declaration of Helsinki and all procedures involving human subjects were approved by the University of Otago Ethics Committee (reference number D14/288).

\section{References}

1. Alasalvar C \& Bolling BW (2015) Review of nut phytochemicals, fat-soluble bioactives, antioxidant components and health effects. Br J Nutr 113, Suppl. 2, S68-S78.

2. Brufau G, Boatella J \& Rafecas M (2006) Nuts: source of energy and macronutrients. Br J Nutr 96, Suppl. 2, S24-S28.

3. Ros E (2010) Health benefits of nut consumption. Nutrients 2, 652-682.

4. Ministry of Health (2015) Eating and Activity Guidelines for New Zealand Adults. Wellington: Ministry of Health.

5. National Health and Medical Research Council (2013) Australian Dietary Guidelines. Canberra: NHMRC.

6. Nordic Council of Ministers (2014) Nordic Nutrition Recommendations 2012. https://www.norden.org/en/theme/ former-themes/themes-2016/nordic-nutrition-recommendation/ nordic-nutrition-recommendations-2012 (accessed September 2017).

7. US Department of Health and Human Services \& US Department of Agriculture (2015) 2015-2020 Dietary Guidelines for Americans, 8th ed. http://www.health.gov/dietary guidelines/2015/guidelines/ (accessed November 2017).

8. Grosso G, Yang J, Marventano S et al. (2015) Nut consumption and all-cause, cardiovascular, and cancer mortality risk: a systematic review and meta-analysis of epidemiologic studies. Am J Clin Nutr 101, 783-793.

9. Hshieh TT, Petrone AB, Gaziano JM et al. (2015) Nut consumption and risk of mortality in the Physicians' Health Study. Am J Clin Nutr 101, 407-412. 
10. Kris-Etherton PM, Yu-Poth S, Sabate J et al. (1999) Nuts and their bioactive constituents: effects on serum lipids and other factors that affect disease risk. Am J Clin Nutr 70, 3 Suppl., S504-S511.

11. Nash SD \& Nash DT (2008) Nuts as part of a healthy cardiovascular diet. Curr Atheroscler Rep 10, 529-535.

12. Sabate J, Oda K \& Ros E (2010) Nut consumption and blood lipid levels: a pooled analysis of 25 intervention trials. Arch Intern Med 170, 821-827.

13. Tey S, Brown R \& Chisholm A (2012) Nuts and Heart Health. National Heart Foundation of New Zealand Evidence-Based Position Statement on the Relationship of Nuts to Heart Health. Auckland: National Heart Foundation of New Zealand.

14. US Food and Drug Administration (2003) Qualified Health Claims: Letter of Enforcement Discretion - Nuts and Coronary Heart Disease (Docket No 02P-0505). http://www. fda.gov/Food/IngredientsPackagingLabeling/Labeling Nutrition/ucm072926.htm (accessed September 2013).

15. Willett WC, Sacks F, Trichopoulou A et al. (1995) Mediterranean diet pyramid: a cultural model for healthy eating. Am J Clin Nutr 61, 6 Suppl., 1402S-1406S.

16. Pawlak R, Colby S \& Herring J (2009) Beliefs, benefits, barriers, attitude, intake and knowledge about peanuts and tree nuts among WIC participants in eastern North Carolina. Nutr Res Pract 3, 220-225.

17. Pawlak R, London HA, Colby SE et al. (2012) Perception of nut intake among individuals with or at risk for heart disease and/or diabetes. J Behav Health 1, 185-188.

18. Brown RC, Tey SL, Gray AR et al. (2014) Patterns and predictors of nut consumption: results from the 2008/09 New Zealand Adult Nutrition Survey. Br J Nutr 112, 2028-2040.

19. Jenab M, Sabate J, Slimani N et al. (2006) Consumption and portion sizes of tree nuts, peanuts and seeds in the European Prospective Investigation into Cancer and Nutrition (EPIC) cohorts from 10 European countries. Br J Nutr 96, Suppl. 2, S12-S23.

20. O'Neil CE, Keast DR, Nicklas TA et al. (2012) Out-of-hand nut consumption is associated with improved nutrient intake and health risk markers in US children and adults: National Health and Nutrition Examination Survey 1999-2004. Nutr Res 32, 185-194.

21. O'Neil CE, Nicklas TA \& Fulgoni VL (2015) Tree nut consumption is associated with better nutrient adequacy and diet quality in adults: National Health and Nutrition Examination Survey 2005-2010. Nutrients 7, 595-607.

22. Tey SL, Brown R, Chisholm A et al. (2011) Current guidelines for nut consumption are achievable and sustainable: a hazelnut intervention. Br J Nutr 105, 1503-1511.

23. Tey SL, Gray AR, Chisholm AW et al. (2013) The dose of hazelnuts influences acceptance and diet quality but not inflammatory markers and body composition in overweight and obese individuals. J Nutr 143, 1254-1262.

24. American Nurses Association (2015) Nurses Rank as Most Honest, Ethical Profession for 14th Straight Year (12/21/15). http://www.nursingworld.org/FunctionalMenuCategories/ MediaResources/PressReleases/2015-NR/Nurses-Rank-asMost-Honest-Ethical-Profession-for-14th-Straight-Year.html (accessed September 2016).

25. Roy Morgan Research (2016) Roy Morgan Image of Professions Survey 2016: Nurses still easily most highly regarded - followed by Doctors, Pharmacists \& Engineers. http:// www.roymorgan.com/findings/6797-image-of-professions2016-201605110031 (accessed September 2016).

26. Brown RC, Yong LC, Gray AR et al. (2017) Perceptions and knowledge of nuts amongst health professionals in New Zealand. Nutrients 9, 220-220.

27. Dillman D (2011) Mail and Internet Surveys: The Tailored Design Method - 2007 Update with New Internet, Visual, and Mixed-Mode Guide, 2nd ed. Hoboken, NJ: John Wiley \& Sons, Inc.
28. Statistics New Zealand (2005) The Statistical Standard for Ethnicity 2005. Wellington: Statistics New Zealand.

29. Peduzzi P, Concato J, Kemper E et al. (1996) A simulation study of the number of events per variable in logistic regression analysis. J Clin Epidemiol 49, 1373-1379.

30. Cochran WG (1954) Some methods for strengthening the common $\chi^{2}$ tests. Biometrics 10, 417-451.

31. Djousse L, Arnett DK, Carr JJ et al. (2005) Dietary linolenic acid is inversely associated with calcified atherosclerotic plaque in the coronary arteries: the National Heart, Lung, and Blood Institute Family Heart Study. Circulation 111, 2921-2926.

32. Venkatachalam M \& Sathe SK (2006) Chemical composition of selected edible nut seeds. J Agric Food Chem 54, 4705-4714.

33. Thomson CD (2004) Selenium and iodine intakes and status in New Zealand and Australia. Br J Nutr 91, 661-672.

34. Alasalvar C, Pelvan E \& Amarowicz R (2010) Effects of roasting on taste-active compounds of Turkish hazelnut varieties (Corylus avellana L.). J Agric Food Chem 58, 8674-8679.

35. Amaral JS, Casal S, Seabra RM et al. (2006) Effects of roasting on hazelnut lipids. J Agric Food Chem 54, 1315-1321.

36. Schlormann W, Birringer M, Bohm V et al. (2015) Influence of roasting conditions on health-related compounds in different nuts. Food Chem 180, 77-85.

37. He FJ, Li J \& Macgregor GA (2013) Effect of longer term modest salt reduction on blood pressure: Cochrane systematic review and meta-analysis of randomised trials. BMJ 346, f1325.

38. Frecka JM, Hollis JH \& Mattes RD (2008) Effects of appetite, BMI, food form and flavor on mastication: almonds as a test food. Eur J Clin Nutr 62, 1231-1238.

39. McKiernan F, Lokko P, Kuevi A et al. (2010) Effects of peanut processing on body weight and fasting plasma lipids. Br J Nutr 104, 418-426.

40. Tey SL, Robinson T, Gray AR et al. (2017) Do dry roasting, lightly salting nuts affect their cardioprotective properties and acceptability? Eur J Nutr 56, 1025-1036.

41. Jiang R, Manson JE, Stampfer MJ et al. (2002) Nut and peanut butter consumption and risk of type 2 diabetes in women. JAMA 288, 2554-2560.

42. Li TY, Brennan AM, Wedick NM et al. (2009) Regular consumption of nuts is associated with a lower risk of cardiovascular disease in women with type 2 diabetes. J Nutr 139, $1333-1338$.

43. Luu HN, Blot WJ, Xiang YB et al. (2015) Prospective evaluation of the association of nut/peanut consumption with total and cause-specific mortality. JAMA Intern Med 175, 755-766.

44. van den Brandt PA \& Schouten LJ (2015) Relationship of tree nut, peanut and peanut butter intake with total and cause-specific mortality: a cohort study and meta-analysis. Int J Epidemiol 44, 1038-1049.

45. Ministry of Health (2014) Annual Update of Key Results 2012/14: New Zealand Health Survey. Wellington: Ministry of Health.

46. Lee C, Dobson AJ, Brown WJ et al. (2005) Cohort profile: the Australian longitudinal study on women's health. Int J Epidemiol 34, 987-991.

47. Timperio A, Cameron-Smith D, Burns C et al. (2000) Physical activity beliefs and behaviours among adults attempting weight control. Int J Obes Relat Metab Disord 24, 81-87.

48. Martikainen P, Laaksonen M, Piha K et al. (2007) Does survey non-response bias the association between occupational social class and health? Scand J Public Health 35, 212-215.

49. Mealing NM, Banks E, Jorm LR et al. (2010) Investigation of relative risk estimates from studies of the same population with contrasting response rates and designs. BMC Med Res Methodol 10, 26.

50. Van Loon AJ, Tijhuis M, Picavet HS et al. (2003) Survey nonresponse in the Netherlands: effects on prevalence estimates and associations. Ann Epidemiol 13, 105-110. 